\title{
Risk Assessment of Gas Condensates Export Pipelines by Indexing Method (Case Study: Special Economic Energy Zone of South Pars-Assaluyeh)
}

\author{
Amin Zargari Kolaei ${ }^{1}$, Mahnaz Nasrabadi ${ }^{1} \&$ Saeid Givehchi $^{2}$ \\ ${ }^{1}$ Department of Environment Management (HSE), Faculty of Engineering and Technology, Zahedan Branch, \\ Islamic Azad University, Zahedan, Iran \\ ${ }^{2}$ Faculty of Environment Science, University of Tehran, Tehran, Iran \\ Correpondence: Mahnaz Nasrabadi, Department of Environment Management (HSE), Faculty of Engineering \\ and Technology, Zahedan Branch, Islamic Azad University, Zahedan, Iran. E-mail: nilofar.nasr63@gmail.com
}

\author{
Received: January 1, 2017 \\ Accepted: January 15, 2017 Online Published: May 31, 2017 \\ doi:10.5539/jsd.v10n3p175 \\ URL: https://doi.org/10.5539/jsd.v10n3p175
}

\begin{abstract}
Due to the sensitivity and vital and undeniable role of gas energy in the energy basket of the country, especially in economy, evaluation of risk assessment studies on the designing and exploiting of this massive and extensive industry including oil and gas pipelines seems to be very necessary. Generally, risk assessment is process of the determining the risk quantity and quality by analyzing potential risks in the project which will be done by taking into account the sensitivity or vulnerability of the surrounding environment. kent Muhlbauer's method based on relative scoring of parameters that are involved in risks creation deals with the risk assessment. In order to establishment this system for risk assessment of statistical data collection, due to the failure of Iranian oil and gas pipelines, experts and scholars' experiences as a field project (South Pars gas condensate export pipeline) were collected. According to the existing conditions and availability of information sources in the Iranian oil and gas industry, finally, these data as safety risk assessment criteria of pipelines were processed in a graph and scoring was conducted based on the relative weighting of risk starter elements in the pipeline. according to the obtained scores and the relative risk of different areas of pipeline by considering $\mathrm{km}$ scale of areas, it was identified that $16 \%$ of the total pipeline had very high risk level, $34 \%$ of the total pipeline had high risk level, $34 \%$ of the total pipeline had medium risk level and $16 \%$ of the pipeline had low risk level
\end{abstract}

Keywords: risk, pipeline, gas condensate, indexing, Kent Muhlbauer

\section{Introduction}

\subsection{Introduce the Problem}

Oil and gas from the first days of the eruption, always have been the driving force of the society towards progress and development and Iran with more than 30,000 kilometers of oil and gas transmission pipelines, is one of the leading countries in the operation and exploitation of this huge and valuable infrastructure. Oil and gas pipelines have been considered as the main pillars of the transfer process and according to the expansion of these lines in different facility or even residential regions and high potential of vulnerability, pipeline safety is of utmost importance [8]. Environmental risk assessment is a potential qualitative and quantitative risk analysis process and by considering sensitivity or vulnerability of its surrounding environment, it is the prediction process of potential risk [12]. Iranian Oil Terminals Company, with respect to the development of oil and gas fields and 20 -year vision of development of the oil industry and the subsequent development of gas condensates export, since 2003 is located in the South Pars region and now export, totally, 600 thousand gas condensates barrels per day through pipelines and the floating buoy which are produced by South Pars refineries. So traversing a relatively long way from production to export requires a safety management system and detailed assessment at any time and any negligence and error will cause financial losses, losses in lives and damage to the environment [Map1, 2 and Figure 1]. Nowadays, safety knowledge as an integral part of human life has always been used in reducing adverse events and incidents, especially in the industrial sector of each country [14]. Now in all over the world, the pipeline risk assessment is done by methods such as FMEA / FTA/HAZOP that each has its own advantages but the new appraisal method that is designed by Kent Muhlbauer is devoted to pipelines risk 
assessment and now in our country, the need of using this method for planning and managing is felt and some processes have been done on the natural gas transmission pipelines $[2,5,6]$. In this study, it is intended that after a thorough acquaintance with operational processes of the transfer and Gas Condensates export, to take into account the examining and evaluating process of the pipelines risks of by indexing method; that its result leads to approaches for reducing or eliminating risks of the current activities, decreasing faults and reducing the environmental impact of gas pipelines and the promoting installations safety and the continuing the export process [1]. Therefore this research seems to be necessary. Goudarzi et al (2012), conduct a study entitled "Pipeline risk assessment by using indigenous Kenneth Muhlbauer methods, case study: Qazvin-Delijan gas pipeline" that according to the obtained results with this method, it was concluded that $32 \%$ of the pipeline had very high risk level, $11 \%$ of the total pipeline had high risk level, $23 \%$ of the pipeline had medium risk level and $34 \%$ of the total had low risk level [3].

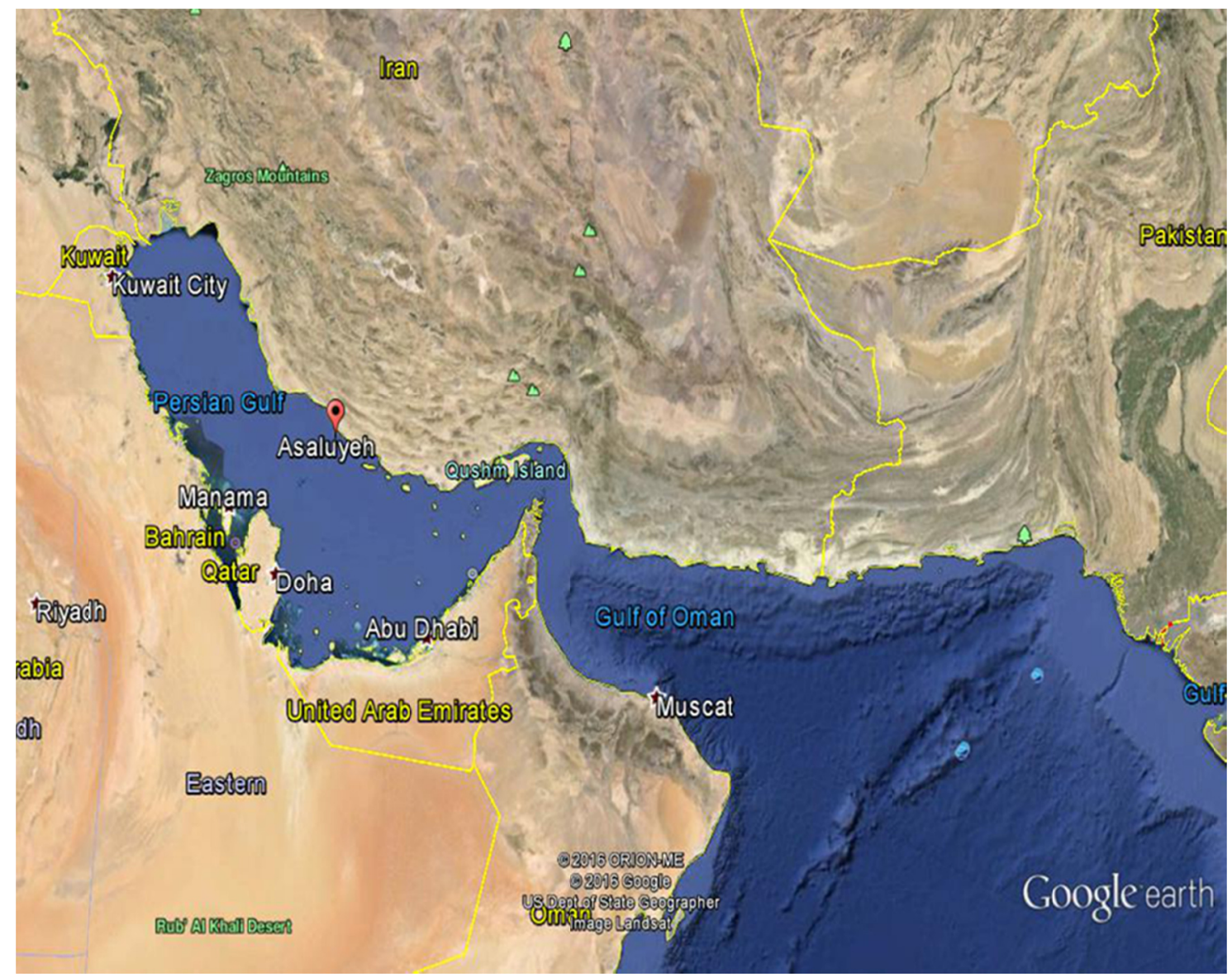

Map 1. Satellite map of the location of case study 


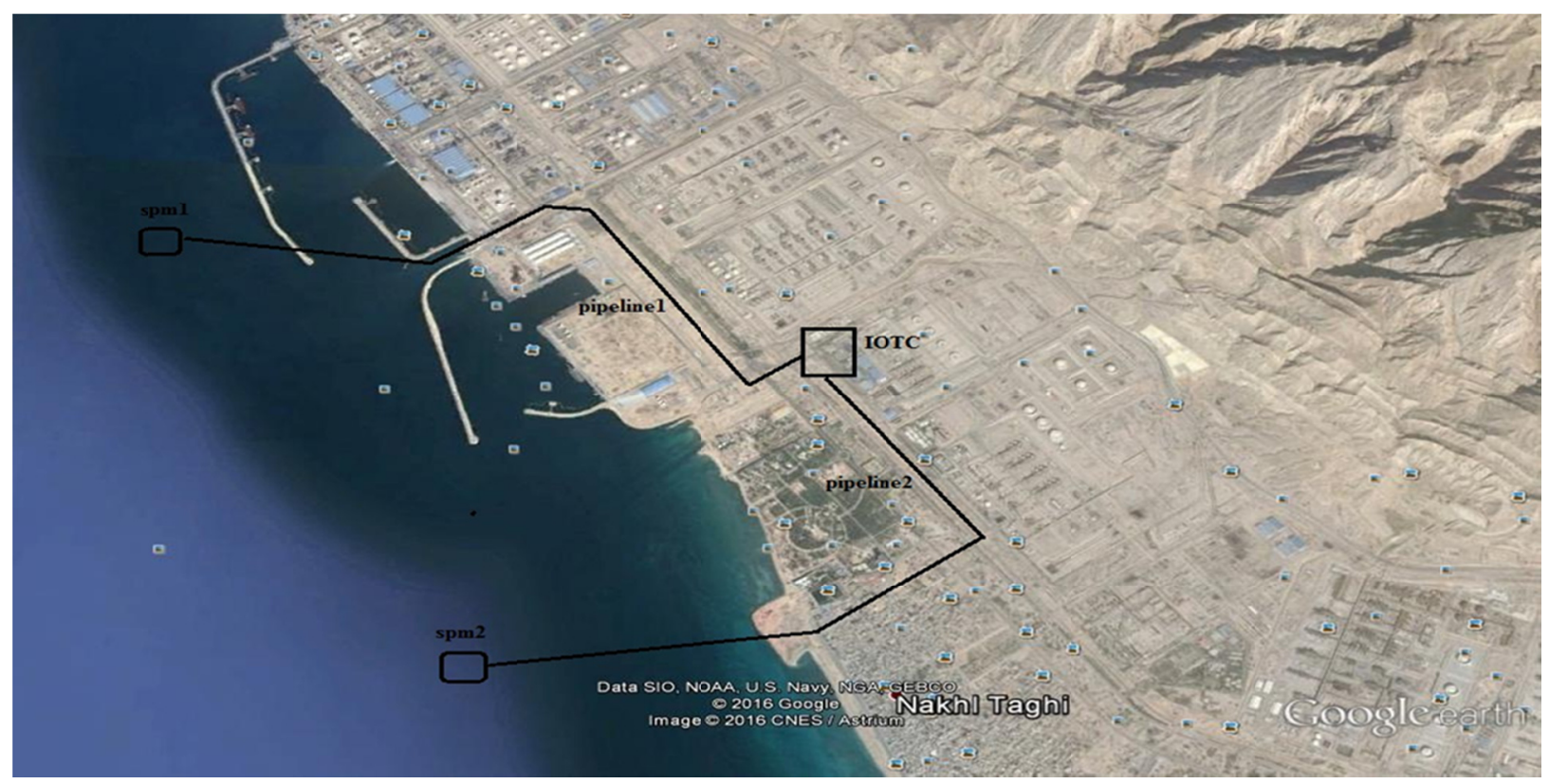

Map 2. Satellite map of the pipeline route of case study

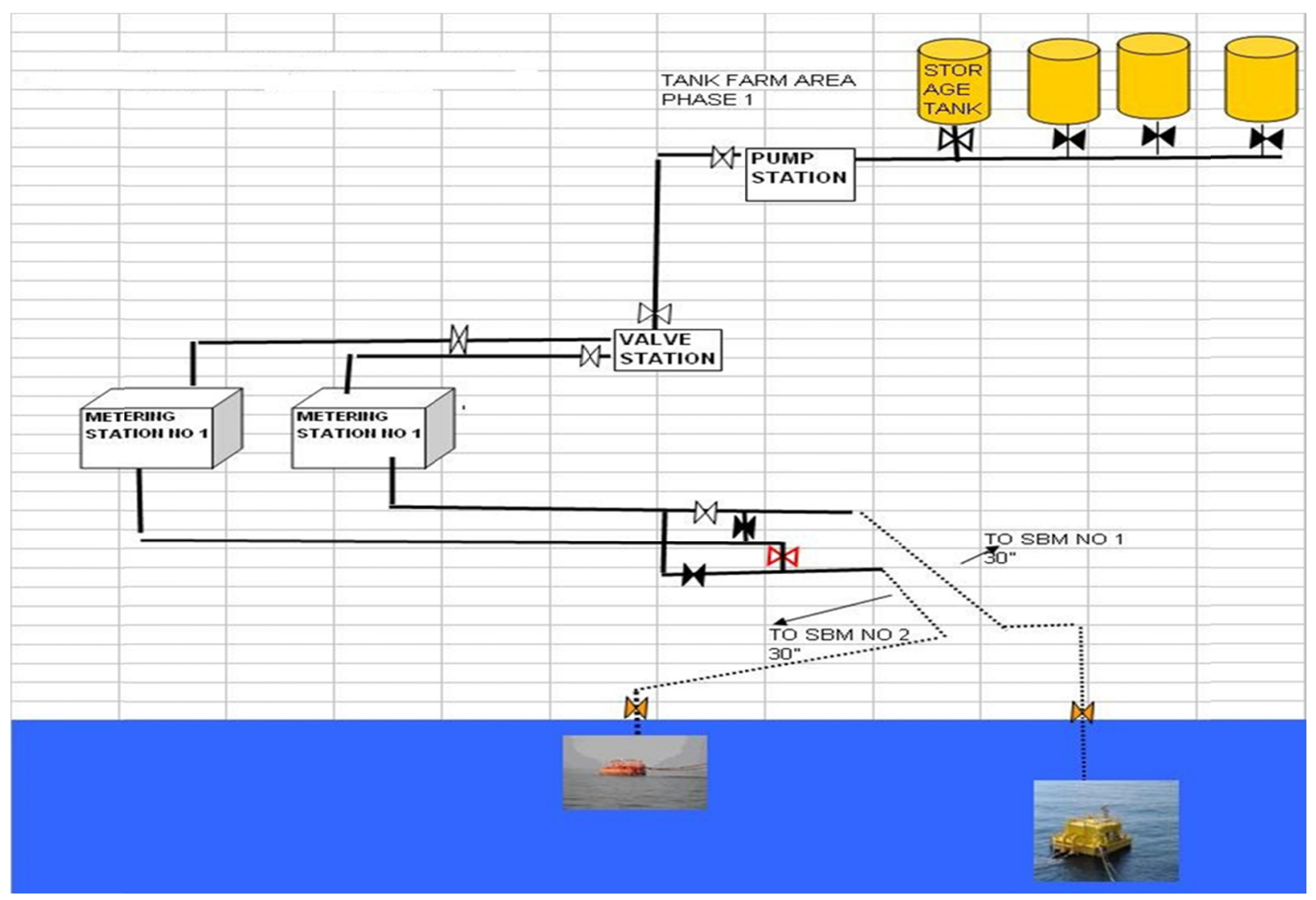

Figure 1. The pipeline route diagram of case study

\section{Method}

In this research, for collecting data, library method and analyzing documentation of under study area gas pipeline and comparing data recorded in the comprehensive maintenance system that it was used as software in the company were done and based on indexing method (on the basis of W. Kent Muhlbauer Method) in an identified 
assessment system and finally, with regard to range of scores and history studied by experts and administrative connoisseurs, risk assessment was carried out. [4, 9] The population of this study, in terms of questionnaire respondents, was National Iranian Oil Company experts in engineering, implementation and maintenance and statistical sample of officials as respondents in the study are relevant to these pipelines. Statistical population of this study in terms of pipelines was Assaluyeh export pipelines and in terms of samples selection for pipelines risk assessment was gas condensates exporting pipeline which are produced at gas refineries located in South Pars [Figure 2]. Indexing method(on the basis of W. Kent Muhlbauer Method) calculated pipelines risks and the possible threats in pipeline which are third party damage pipelines risks, corrosion, design and incorrect operation were calculated by a relative scoring system. [10] In other words, first the main risk factors were defined and Algebraically summed in each stage and the total risks index for different parts of the pipeline were obtained and health and environmental risk factors for these periods were calculated and multiplied together and we determine the severity of leakage impact index [11] and finally levels of safety risk factors of each section were divided based on health and environmental risk factors that the resulting number shows relative risk of any section of pipeline and easily by observing the risk level of pipeline section, the critical points can be determined and we can plan to reduce critical points and eventually using tables and graphs the final analysis is done. [13]

The associated formulas are:

Total Risk $($ Sum Index) $=$ Third party damage Index + Corrosion Index + Design Index + Incorrect operation Index

Leak impact factors index $=$ Product hazard* leak volume * Dispersion* Receptors

Relative risk Score $=$ Total Risk Index divided by the Leakage impact factors index

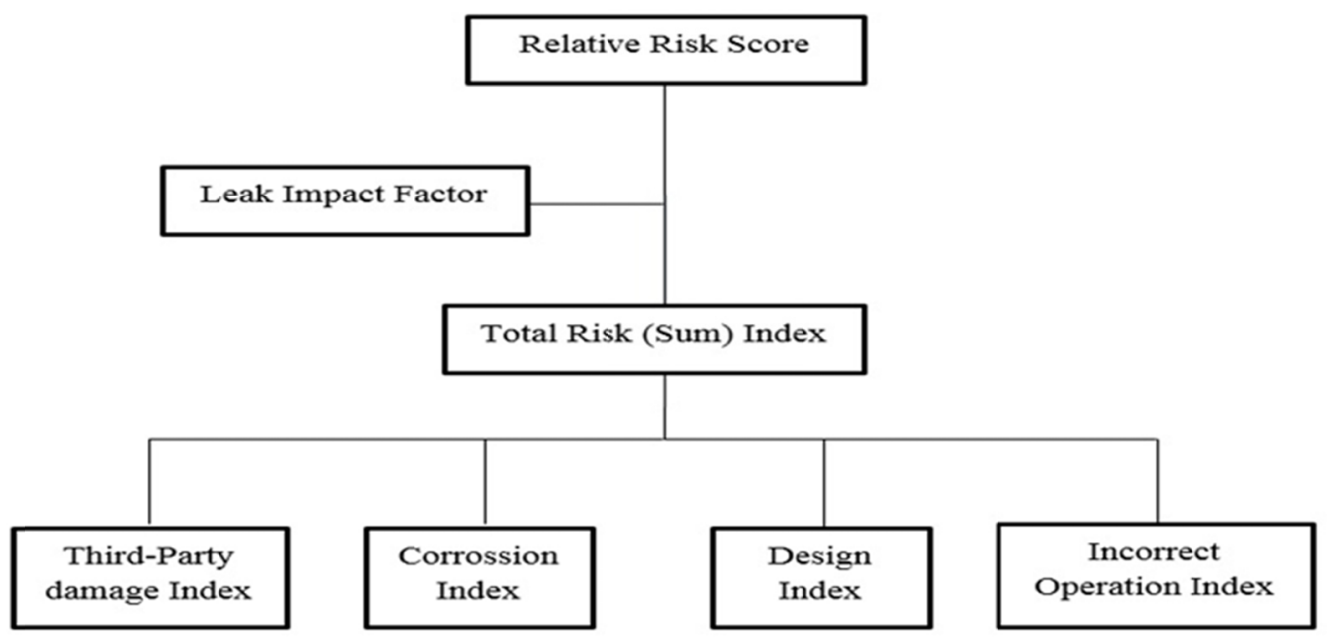

Figure 2. Risk assessment model by indexing method

The first step in the risk assessment of gas condensates export pipelines is division of pipeline to obtain the risk number. In this study the pipelines dividing was done based on dynamic approach and the under study pipeline has been divided into 6 sections [Table 1] that was used as the most appropriate method for division of lines and based on criteria such as population density surrounding the pipeline, pipe thickness, pipe diameter [Table 2] and the equipment on the ground, markers, the area surrounding the pipeline (with regard to construction, type of land use change) and natural features this division was done.

Table 1. Pipelines division of case study

\begin{tabular}{ccccccc}
\hline Pipeline length & Section 1 & Section2 & Section3 & Section4 & Section5 & Section6 \\
\hline $\mathbf{1 1 9 3 3} \mathbf{~ m}$ & $150 \mathrm{~m}$ & $2000 \mathrm{~m}$ & $1700 \mathrm{~m}$ & $1631 \mathrm{~m}$ & $3800 \mathrm{~m}$ & $2652 \mathrm{~m}$ \\
\hline
\end{tabular}


Table 2. Pipeline characteristics of case study

\begin{tabular}{|c|c|c|c|c|c|c|}
\hline Pipe material & $\begin{array}{c}\text { Pipe } \\
\text { Diameter }\end{array}$ & Thickness & Coverage type & $\begin{array}{c}\text { Designing } \\
\text { Pressure }\end{array}$ & $\begin{array}{c}\text { Operating } \\
\text { pressure }\end{array}$ & $\begin{array}{c}\text { Product } \\
\text { temperature }\end{array}$ \\
\hline $\begin{array}{c}\text { Carbon-Steel } \\
\text { Pipeline } \\
\text { API =5LX52 }\end{array}$ & 30 Inches & $15.9 \mathrm{~mm}$ & $\begin{array}{l}\text { Three-layer } \\
\text { polyethylene }\end{array}$ & Psi 300 & 90 Psi & $20-45^{\circ} \mathrm{C}$ \\
\hline
\end{tabular}

\section{Results}

In this study, according to the conducted studies, dynamic method has been used in the pipeline division. Since the under study area contained Manifold valves stations and installations for the measurement of gas condensates export pipelines from refineries, during the 11-kilometer of the pipeline, manifold taps, climate change, pipeline circumstances and pipeline route change were used as dividing point. In [Table 3] the third-party damage index variables and points are shown.

Table 3. Assessment of third-party damage index variables

\begin{tabular}{|c|c|c|c|c|c|c|}
\hline Pipeline & Section 1 & Section 2 & Section 3 & Section 4 & Section 5 & Section 6 \\
\hline & \multicolumn{6}{|c|}{ Depth of cover } \\
\hline Score & 20 & 20 & 20 & 20 & 20 & 20 \\
\hline \multirow[t]{2}{*}{ Description / Calculations } & Surface of the ground & Underground & Underground & Underwater & Underground & Underwater \\
\hline & \multicolumn{6}{|c|}{ Activity Level } \\
\hline Score & 8 & 8 & 8 & 15 & 8 & 15 \\
\hline \multirow[t]{2}{*}{ Description / Calculations } & & Medium & & Low & Medium & Low \\
\hline & \multicolumn{6}{|c|}{ Aboveground Facilities } \\
\hline Score & 10 & 7 & 0 & 10 & 7 & 10 \\
\hline \multirow[t]{2}{*}{ Description / Calculations } & \multicolumn{6}{|c|}{ Pipelines junction / conveyor construction and Pardis petrochemical Campus / pipeline passageway } \\
\hline & \multicolumn{6}{|c|}{ Identification of risk location } \\
\hline Score & 15 & 15 & 15 & 15 & 15 & 15 \\
\hline \multirow[t]{2}{*}{ Description / Calculations } & \multicolumn{6}{|c|}{ Case study in site one and under the supervision of South Pars Special Economic Zone } \\
\hline & \multicolumn{6}{|c|}{ Public education } \\
\hline Score & 15 & 15 & 15 & 15 & 15 & 15 \\
\hline \multirow[t]{2}{*}{ Description / Calculations } & \multicolumn{6}{|c|}{ Joint meetings between the oil and gas companies and local authorities } \\
\hline & \multicolumn{6}{|c|}{ Right-of- way conditions } \\
\hline Score & 5 & 2 & 2 & 3 & 4 & 3 \\
\hline \multirow[t]{2}{*}{ Description / Calculations } & Great & Medium & Medium & Good & Good & Good \\
\hline & \multicolumn{6}{|c|}{ Patrol Frequency and inspection } \\
\hline Score & 15 & 15 & 12 & 12 & 15 & 12 \\
\hline Description / Calculations & & & Limi & tion & & Limitation \\
\hline Third party damage index & 88 & 82 & 72 & 90 & 84 & 90 \\
\hline
\end{tabular}

In [Table 4] corrosion index variables and Scores are shown: 
Table 4. Assessment of corrosion index variable

\begin{tabular}{|c|c|c|c|c|c|c|}
\hline Pipeline & Section 1 & Section 2 & Section 3 & Section 4 & Section 5 & Section 6 \\
\hline & \multicolumn{6}{|c|}{ Atmospheric Exposures } \\
\hline Score & 4 & 4 & 5 & 5 & 4 & 5 \\
\hline Description / Calculations & \multicolumn{2}{|l|}{ Soil - air interface } & & \multicolumn{3}{|c|}{ Soil - air interface } \\
\hline & \multicolumn{6}{|c|}{ Atmospheric Type } \\
\hline Score & 1.2 & 0.5 & 0.8 & 0.8 & 0.8 & 0.8 \\
\hline \multirow[t]{2}{*}{ Description / Calculations } & $\begin{array}{l}\text { Extreme humidity and high } \\
\text { temperature }\end{array}$ & \multicolumn{5}{|c|}{ Chemical and extreme humidity / marine and wetland-coastal } \\
\hline & \multicolumn{6}{|c|}{ Atmospheric Coating } \\
\hline Score & 5 & 3 & 3 & 3 & 3 & 3 \\
\hline \multicolumn{7}{|l|}{ Description / Calculations } \\
\hline & \multicolumn{6}{|c|}{ Product Corrosivity } \\
\hline Score & 7 & 7 & 7 & 7 & 7 & 7 \\
\hline Description / Calculations & \multicolumn{6}{|c|}{ Gas condensates corrosion is not including and corrosive under certain conditions is possible } \\
\hline & \multicolumn{6}{|c|}{ Corrosion prevention } \\
\hline Score & 10 & 3 & 3 & 3 & 3 & 3 \\
\hline \multirow[t]{2}{*}{ Description / Calculations } & Observations & Pigging, int & 1 laminated & inhibiting st & s injections & taken place. \\
\hline & \multicolumn{6}{|c|}{ Soil corrosivity } \\
\hline Score & 15 & 9.25 & 9.25 & 7 & 9.25 & 7 \\
\hline \multirow[t]{2}{*}{ Description / Calculations } & \multicolumn{6}{|c|}{$\begin{array}{l}1000-15,000 \mathrm{ohm}-\mathrm{cm} \text { soil resistance and corrosion average, } \mathrm{pH}=4-8 \text { suitable, humidity } 20-30 \% \text { and microbially } \\
\text { induced corrosion (MIC) was not observed. }\end{array}$} \\
\hline & \multicolumn{6}{|c|}{ Mechanical Corrosion } \\
\hline Score & 3 & 3 & 3 & 3 & 3 & 3 \\
\hline \multirow[t]{2}{*}{ Description / Calculations } & \multicolumn{6}{|c|}{$\begin{array}{l}\text { Operating pressure of less than } 60 \% \text { of the submission (Design pressure), operating temperature less than } 38^{\circ} \mathrm{C} \text {, above } \\
10 \text { years old pipeline and three-layer polyethylene coating system of pipes }\end{array}$} \\
\hline & \multicolumn{6}{|c|}{ Cathodic protection } \\
\hline Score & 15 & 0.15 & 0.15 & 1.5 & 1.5 & 1.5 \\
\hline \multirow[t]{2}{*}{ Description / Calculations } & \multicolumn{6}{|c|}{ No cathodic protection system / The distance between test point $<1.5 \mathrm{~km}$} \\
\hline & \multicolumn{6}{|c|}{ AC current interferences } \\
\hline Score & 2 & 2 & 3 & 3 & 2 & 3 \\
\hline Description / Calculations & $63 \mathrm{Kv}$ & $20 \mathrm{Kv}$ & $\begin{array}{r}\text { The abse } \\
\text { transm }\end{array}$ & $\begin{array}{l}\text { of power } \\
\text { n lines }\end{array}$ & $20 \mathrm{Kv}$ & None \\
\hline
\end{tabular}

Impact of guards

$\begin{array}{llllll}\text { Score } & 1 & 1 & 1 & 1 & 1\end{array}$

Description / Calculations

At the crossing point and underpass there are necessary contrivance

\begin{tabular}{ccccccc} 
& \multicolumn{5}{c}{ DC current interference } \\
Score & 7 & 5.5 & 1.5 & 7 & 7 & 6.5 \\
Description / Calculations & None & There are 20 pipeline cross and parallel to gas condensate pipeline. & 7
\end{tabular}

\begin{tabular}{cccccc} 
Description / Calculations & None & \multicolumn{4}{c}{ There are 20 pipeline cross and parallel to gas condensate pipeline. } \\
\hline & \multicolumn{5}{c}{ Pipe covering } \\
\hline Score & 25 & 25 & 25 & 25 & 25 \\
\hline Description / Calculations & \multicolumn{5}{c}{ Three layer polyethylene coverage } \\
\hline Total corrosion index (0-100) & 95.2 & 63.4 & 61.7 & 66.3 & 66.05 \\
\hline
\end{tabular}

Design Index variables and scores are shown in [Table 5]: 
Table 5. Assessment of corrosion index variable

\begin{tabular}{|c|c|c|c|c|c|c|}
\hline Pipeline & Section 1 & Section 2 & Section 3 & Section 4 & Section 5 & Section 6 \\
\hline & \multicolumn{6}{|c|}{ Pipe safety factor } \\
\hline Specifications & \multicolumn{6}{|c|}{ Flange, Valve, Pipeline Class300, Thickness: $15.9 \mathrm{~mm}$} \\
\hline Score & 35 & 35 & 35 & 35 & 35 & 35 \\
\hline Description / Calculations & \multicolumn{6}{|c|}{6 times operating and utilization pressure (90psi) and design pressure $300 \mathrm{psi}$} \\
\hline & \multicolumn{6}{|c|}{ Fatigue stresses } \\
\hline Score & 9 & 9 & 9 & 9 & 9 & 9 \\
\hline Description / Calculations & \multicolumn{6}{|c|}{ stress cycles $1000-10000$ since the establishment of, MAOP $=30 \%$} \\
\hline & \multicolumn{6}{|c|}{ surge potential } \\
\hline Score & 5 & 5 & 5 & 5 & 5 & 5 \\
\hline Description / Calculations & \multicolumn{6}{|c|}{ Depending on the type of fluid, low pressure and low speed in pipeline the possible surge potential is low } \\
\hline & \multicolumn{6}{|c|}{ Integrity verifications } \\
\hline Score & 15 & 15 & 15 & 15 & 15 & 15 \\
\hline Description / Calculations & \multicolumn{6}{|c|}{ Hydrostatic test of pipes has not been done for more than 10 years } \\
\hline & \multicolumn{6}{|c|}{ Land movements } \\
\hline Score & 15 & 5 & 10 & 10 & 10 & 10 \\
\hline Description / Calculations & None & Medium & \multicolumn{4}{|c|}{ Low } \\
\hline Total corrosion index $(0-100)$ & 79 & 69 & 74 & 74 & 74 & 74 \\
\hline
\end{tabular}

In [Table 6] incorrect operations index variables and scores are shown:

Table 6. Assessment of corrosion index variable

\begin{tabular}{ccccccc}
\hline Pipeline & Section 1 & Section 2 & Section 3 & Section 4 & Section 5 & Section 6 \\
\hline Design & \multicolumn{5}{c}{ Hazard identification } \\
\hline Score & 3 & 3 & 3 & 3 & 3 \\
\hline Description / Calculations & \multicolumn{7}{c}{ HAZID \& HAZOP studies are performed at the time of design } \\
\hline Possibility of M.O.P & 5 & 5 & Maximum design pressure \\
\hline Score & & 5 & 5 & 5 & 5 \\
\hline
\end{tabular}

Description / Calculations Unlikely (application error, Installation of pump on specific status and accidental obstruction of middle way valves and human error)

\begin{tabular}{|c|c|c|c|c|c|c|}
\hline \multirow[b]{2}{*}{ Score } & \multicolumn{6}{|c|}{ Safety systems } \\
\hline & 5 & 5 & 5 & 5 & 5 & 5 \\
\hline \multirow[t]{2}{*}{ Description / Calculations } & \multicolumn{6}{|c|}{ Level 1 safety systems / remote view system / control of some control valves } \\
\hline & \multicolumn{6}{|c|}{ Material selection } \\
\hline Score & 2 & 2 & 2 & 2 & 2 & 2 \\
\hline \multirow[t]{2}{*}{ Description / Calculations } & \multicolumn{6}{|c|}{ Evaluation and inspection of the product pipeline has been done by the national oil company. } \\
\hline & \multicolumn{6}{|c|}{ Checks (inspection and control) } \\
\hline Score & 2 & 2 & 2 & 2 & 2 & 2 \\
\hline Description / Calculations & \multicolumn{6}{|c|}{ Ratification and Signature of the construction and executive plans are approved. } \\
\hline Construction & \multicolumn{6}{|c|}{ Inspection in Manufacturing } \\
\hline Score & 10 & 10 & 10 & 10 & 10 & 10 \\
\hline
\end{tabular}

Description / Calculations

Company supervising engineers adequately monitor the correct implementation of the pipeline. 


\begin{tabular}{|c|c|c|c|c|c|c|}
\hline Score & 2 & 2 & 2 & 2 & 2 & 2 \\
\hline Description / Calculations & \multicolumn{6}{|c|}{ According to the existing documents they were approved by supervision engineers. } \\
\hline & \multicolumn{6}{|c|}{ Joining(Welding and fittings) } \\
\hline Score & 2 & 2 & 2 & 2 & 2 & 2 \\
\hline Description / Calculations & \multicolumn{6}{|c|}{ Inspection of froth and radiological examination was conducted by supervising engineers } \\
\hline & \multicolumn{6}{|c|}{ Backfill } \\
\hline Score & 2 & 1 & 2 & 2 & 2 & 2 \\
\hline Description / Calculations & \multicolumn{6}{|c|}{ Seasonal heavy rainfall, picking up the side walls of pipeline } \\
\hline & \multicolumn{6}{|c|}{ Transport and maintain } \\
\hline Score & 2 & 2 & 2 & 2 & 2 & 2 \\
\hline Description / Calculations & \multicolumn{6}{|c|}{ Pipeline transportation and maintenance has been assessed within acceptable limits } \\
\hline & \multicolumn{6}{|c|}{ Insulation } \\
\hline Score & 2 & 2 & 2 & 2 & 2 & 2 \\
\hline
\end{tabular}

Description / Calculations $\quad$ Froth insulation and padding underneath the pipe embankment and channel tune up is within acceptable limits

\begin{tabular}{ccccccc}
\hline Operation & \multicolumn{5}{c}{ Guidelines and Standards and procedures } \\
\hline Score & 5 & 5 & 5 & 5 & 5 & 5 \\
\hline
\end{tabular}

Description / Calculations

SCADA (Supervisory control and data acquisition) / Communication

$\begin{array}{lllllll}\text { Score } & 1 & 1 & 1 & 1 & 1 & 1\end{array}$

Description / Calculations In the pipeline system the SCADA system is not complete, yet $80 \%$ Of system is controlled by operator

\begin{tabular}{|c|c|c|c|c|c|c|}
\hline \multicolumn{7}{|c|}{ Drug testing } \\
\hline Score & 1 & 1 & 1 & 1 & 1 & 1 \\
\hline Description / Calculations & \multicolumn{6}{|c|}{ Except from the recruitment time there is no other evidence of personnel drug testing. } \\
\hline \multicolumn{7}{|c|}{ Safety programs } \\
\hline Score & 1 & 1 & 1 & 1 & 1 & 1 \\
\hline Description / Calculations & \multicolumn{6}{|c|}{ Safety program is designed but it is not with a high level of participation of workers cooperation } \\
\hline \multicolumn{7}{|c|}{ Reviews, maps, archive } \\
\hline Score & 5 & 3 & 3 & 3 & 3 & 3 \\
\hline Description / Calculations & \multicolumn{6}{|c|}{ Surface facilities are under the control but underground facilities control review are incomplete } \\
\hline \multicolumn{7}{|c|}{ Training } \\
\hline Score & 6 & 6 & 6 & 6 & 6 & 6 \\
\hline
\end{tabular}

Description / Calculations Personnel's basic understanding of the utilization of the pipeline is relatively sufficient, but personnel are not under job related test.

\begin{tabular}{ccccccc}
\hline \multicolumn{7}{c}{ Mechanical error preventers } \\
\hline Score & 5 & 5 & 5 & 5 & 5 \\
\hline Description / Calculations & \multicolumn{7}{c}{ There is no Block Valve along the way of pipelines } \\
\hline \multicolumn{7}{c}{ Maintenance and repairs } \\
\hline Score & 13 & 13 & 13 & 13 & 13 \\
\hline
\end{tabular}

Description / Calculations Desirable documentation and appropriate maintenance program are present and they are commensurate with IPS

$\begin{array}{lllllll}\text { Total incorrect operations } & 76 & 71 & 72 & 72 & 72 & 72\end{array}$

index (0-100)

In [Table 7] leak Impact Factor Index variables and the related scores are shown. 
Table 7. Assessment of corrosion index variable

\begin{tabular}{|c|c|c|c|c|c|c|}
\hline Pipeline & Section 1 & Section 2 & Section 3 & Section 4 & Section 5 & Section 6 \\
\hline \multicolumn{7}{|c|}{ Flammability(Nf) } \\
\hline Score & 3 & 3 & 3 & 3 & 3 & 3 \\
\hline Description / Calculations & \multicolumn{6}{|c|}{ The flash point is less than $100^{\circ} \mathrm{F}$} \\
\hline \multicolumn{7}{|c|}{ Reactivity(Nr) } \\
\hline Score & 0 & 0 & 0 & 0 & 0 & 0 \\
\hline Description / Calculations & \multicolumn{6}{|c|}{ Stable materials that even when heating stay stable and unreactive } \\
\hline & \multicolumn{6}{|c|}{ toxicity(Nh) } \\
\hline Score & 2 & 2 & 2 & 2 & 2 & 2 \\
\hline Description / Calculations & \multicolumn{6}{|c|}{ Medical care is needed when exposed } \\
\hline & \multicolumn{6}{|c|}{ chronic hazard (RQ) } \\
\hline Score & 2 & 2 & 2 & 2 & 2 & 2 \\
\hline \multirow[t]{3}{*}{ Description / Calculations } & \multicolumn{6}{|c|}{ Surface, underground and underwater Pipelines, RQ $=5000$} \\
\hline & \multicolumn{6}{|c|}{$\mathrm{LC} 50=5000 \mathrm{ppm}, \mathrm{LD} 50=3160 \mathrm{mg} / \mathrm{kg}$ skin } \\
\hline & \multicolumn{6}{|c|}{ leak volume } \\
\hline Score & 1 & 1 & 1 & 1 & 1 & 1 \\
\hline Description / Calculations & \multicolumn{6}{|c|}{ pipeline material=API 5LX52 } \\
\hline \multicolumn{7}{|c|}{ Dispersion } \\
\hline Score & 1 & 1 & 1 & 1 & 1 & 1 \\
\hline Description / Calculations & \multicolumn{6}{|c|}{ Soil type (sandy, gravel) } \\
\hline $\begin{array}{l}\text { Receptors and the environment and High } \\
\text { valuable areas }\end{array}$ & \multicolumn{6}{|c|}{$\mathrm{R}=\mathrm{POP}+\mathrm{ENV}+\mathrm{HVA}$} \\
\hline Score & 5.1 & 5.7 & 6.2 & & 5.7 & 5.2 \\
\hline \multirow[t]{2}{*}{ Description / Calculations } & \multicolumn{6}{|c|}{$\begin{array}{c}\text { P }>46 \text {, DOT(Department Of Transportation) TYPE } 3=5 \text { SCORE Adjacent industries, the } \\
\text { industrial estate }\end{array}$} \\
\hline & \multicolumn{6}{|c|}{$\mathrm{LIF}=\mathrm{PH} * \mathrm{LV} * \mathrm{D} * \mathrm{R}$} \\
\hline leak Impact Factors Index & 35.7 & 39.9 & 43.4 & 6.4 & 39.9 & 36.4 \\
\hline
\end{tabular}

Finally in [Tables 8, 9] sum and averages index and in [Tables 10, 11] relative risk score and overall risk assessment are shown:

Table 8. Sum indexes (total risk)

\begin{tabular}{ccccccc}
\hline Pipeline & Section 1 & Section 2 & Section 3 & Section 4 & Section 5 & Section 6 \\
\hline Total third-party damage index & 88 & 82 & 72 & 90 & 84 & 90 \\
Total corrosion index & 95.2 & 63.4 & 61.4 & 66.3 & 66.05 & 66.3 \\
Total design index & 79 & 69 & 74 & 74 & 74 & 74 \\
Total incorrect operations Index & 76 & 71 & 72 & 72 & 72 & 72 \\
Sum indexes (0-400) & 338.2 & 285.4 & 281.4 & 302.3 & 296.05 & 302.3 \\
\hline
\end{tabular}


Table 9. Average of total risk (safety) indexes

\begin{tabular}{ccccc}
\hline Index & Third-party damage index & Corrosion index & Design index & incorrect operations Index \\
\hline Section 1 & 88 & 95.2 & 79 & 76 \\
Section 2 & 82 & 63.4 & 69 & 71 \\
Section 3 & 72 & 61.4 & 74 & 72 \\
Section 4 & 90 & 66.3 & 74 & 72 \\
Section 5 & 84 & 66.05 & 74 & 72 \\
Section 6 & 90 & 66.3 & 74 & 72 \\
Average & 84.3 & 69.77 & 74 & 72.5 \\
\hline
\end{tabular}

Table 10. Average of total risk (safety) indexes

\begin{tabular}{ccccccc}
\hline Pipeline & Section 1 & Section 2 & Section 3 & Section 4 & Section 5 & Section 6 \\
\hline Sum Indexes (SI) & 338.2 & 285.4 & 281.4 & 302.3 & 296.05 & 302.3 \\
leak Impact Factor Index (LIF) & 35.7 & 39.9 & 43.4 & 36.4 & 39.9 & 36.4 \\
Relative Risk score (SI/LIF) & 9.47 & 7.15 & 6.48 & 8.3 & 7.4 & 8.3 \\
\hline
\end{tabular}

Table 11. Risk Assessment of gas condensate export pipeline

\begin{tabular}{cccc}
\hline $\begin{array}{c}\text { Pipe } \\
\text { section }\end{array}$ & $\begin{array}{c}\text { Risk } \\
\text { score }\end{array}$ & Risk assessment & Percent (\%) \\
\hline Section 3 & $6-7$ & Very high & 16 \\
Section 2 and 5 & $7-8$ & High & 34 \\
Section 4 and 6 & $8-9$ & Medium & 34 \\
Section 1 & $9-10$ & Low & 16 \\
\hline
\end{tabular}

The obtained results showed that the third-party potential damage index in all areas of the pipeline were in good condition except the second and third sections that the most important factors of scores decreasing were, respectively, crossing the pipe through sulfur installations and other facilities construction (NPC) on the pipeline, lack of dedicated corridor, not specifying the service road (ROW), lack of pipeline safety privacy, non-professional licensing for construction of conveyors and petrochemical facilities on the pipeline by higher authorities without risk assessment and considering the lack of pipeline privacy and fencing and physical protection of a range, that these are increasing factors of risks, so that got lower scores compared with other places that is higher risk indicator of this areas.

The results of the evaluation of corrosion index showed that in most areas of the pipeline poor scores have been obtained. In the first area because of its surface statue, inspection and protection against corrosion were properly carried out and this process showed less risk marker than other areas, and second and third evaluated zones of pipelines have raised the chance lower scores because of 14 pipelines crossover and parallel crossing and presence of annoying and wandering currents, Atmospheric conditions change and high soil moisture in the pipeline route, 10 years old under study pipelines, the absence of integrated cathodic protection systems and pipeline pigging due to different diameters and lack of information about the actual condition of pipelines in this area compared to other areas, that is evident of more risk is in these areas.

The design index results reflect that the obtained scores, although most are in the acceptable range but are not satisfactory in the range of 2 and 3 and the most important reasons of this issue are respectively, unsafe pipeline route selection and unprofessional authority licensing for the construction of other facilities around it, chance of motion and movement of the earth, picking levee wall of the pipeline route and the retrofitting rocks and cover it with just fine soil, constructing channels to collect surface water and washing slag and soil on the pipe and lack of the pipe hydrostatic testing more than 10 years. Evaluation of design index within the second area unlike the previous indexes from the third area has gained lower scores and this issue is due to the above reason that is a sign of higher risk for this area. 
In the assessment of incorrect operation index, it was clarified that with regard to the integrity of the pipeline and the impact of parameters of the index for the entire route as well as its construction by reputable and experienced foreign companies (Total \& Petronas), same and acceptable scores were obtained. However, since in the past years, the results of analysis showed that human errors are the cause of the events that have occurred in gas condensate export pipelines, the assessment conducted is not satisfactory. Among the main reasons for this are, respectively, level one (low level) procedural facilities safety system, lack of SCADA systems, and $80 \%$ operator regulatory system, lack of holding occupational exams related to beneficiary employees, absence of evidence showing drug test after hiring personnel, and lack of optimal worker participation in safety programs designed.

Total results of safety indicators indicate that in the second and third sections, achieved points were not satisfactory and were riskier than other areas. Although the rest of the areas according the maximum safety index score (400) that they can gain in ideal conditions, they did not have acceptable level of scores and they were in the notification area but not paying attention to them can, in not too distant future, cause unwanted events.

So after averaging the safety indicators of the studied range, it was found that the pipelines conditions with regard to the corrosion index and the index of operation and malfunctions are in the worse than the other indices situation that it is necessary to perform precautionary measures related to the aforementioned indicators variables.

The leakage impact factors index results suggest that the leakage impact with respect to the information contained in the gas condensates SDS, NFPA704 standard and DOT 192 classification in the terms of the toxicity and health, environmentally sensitive and economically valuable areas are not in the too acute area and if rating each of the pipelines move toward zero, the severity of the consequences of leakage will be less and the only reason to increase the points of the third, second and fifth areas in compare with other regions will be the crossing of the pipeline from environmentally sensitive and economically valuable areas, and in case of leakage that could have more deleterious effects. The results of the level relative risk index that represents relative risk and total assessment and by dividing the total index with the index of the health risks and environmental impact of the leakage, showed that third section of pipe had very high risk level, the second and fifth section had high risk level, fourth and sixth sections had medium risk level and the first section had low risk level, also relative percentages with regard to the total risk level obtained with respect to the results are as: $16 \%$ of the total pipeline had a very high, $34 \%$ of the pipeline had a high, $34 \%$ of the total pipeline had medium and $16 \%$ of the total pipeline had a low risk level.

\section{Discussion}

The highest risk of plan related to gas condensate leakage and future consequences (fire, explosion, personal accident, environmental pollution...) therefore, it is necessary that in the early designing stages (feasibility) all the factors should be assessed and evaluated using appropriate methods of risk assessment of the pipeline. Moreover, all requirements and standards of implementation and risk management program of pipeline should be considered from the beginning, and in case of making corrections and modify in the pipeline and its environmental conditions, management of change program must be institutionalized and implemented in the company.

Pipelines threatening factors and variables vary from state to state and appropriate preventive measures specific to each region should be considered

\section{References}

Abdoli, M. (2009). Risk assessment oil pipelines, gas and petrochemical on the basis of W.kent Muhlbauer Method, Abghin Rayan Pub.

Brito, A. J., \& de Almeida, A.T. (2008). Multi attribute risk assessment for risk ranking of natural gas pipelines. Reliability Engineering \& System Safety. Retrieved from www.sciencedirect.com

DeWolf, G. B. (2005). Pipeline carrying natural gas. Journal of Hazardous Materials A123, 1-12.

Ghodarzi, H. A., \& Venous, D. (2003). Risk Management. Tehran Neghah-e-Danesh Pub.

Han, Z. Y., \& Weng, W. G. (2011). Comparison study on qualitative and quantitative risk assessment methods for urban natural gas pipeline network.

IEC 608121. (2001). failure mode and effect analysis (FMEA), Procedures for analysis techniques for system reliability.

IEC 618821. (2001). Hazard and operability studies (HAZOP studies), Application guide. 
Keyser, C. A. (1980). Materials Science in Engineering (3rd ed.). Columbus, OH: Charles E, Merrill publishing Co, pp.75-101,131-159.

Lei, M. et al. (2013). A novel method of quantitative risk assessment based on grid difference of pipeline sections.

Martin, D. E. (1998). Methods of Prevention, Detection and Control of Spillages in European Oil Pipelines, Prepared for CONCAWE's Oil Pipelines Management Group Technical Coordinator.

Morgan, B. (1995). The Importance of Realistic Representation of Design Features in the Risk Assessment of High-pressure Gas pipeline, presented at pipeline Reliability Conference, Houston, TX.

Motamedzadeh, M., Mohammadfam, I., \& Hamidi, Y. A. (2009). Health risk assessment, safety and environmental indexing methods Case Study: Kermanshah-Sanandaj oil pipeline, Iran Occupational Health, p, 55-63.

Muhlbauer, W. K. (2004). Pipeline risk management Manual, Gulf professional publishing, United State of America, third Ed: pp572.

Stephenson, J. (1991). System Safety 2000. Van Nostrand Reinhold.

\section{Copyrights}

Copyright for this article is retained by the author(s), with first publication rights granted to the journal.

This is an open-access article distributed under the terms and conditions of the Creative Commons Attribution license (http://creativecommons.org/licenses/by/4.0/). 